\title{
A Pilot Web Based Positive Parenting Intervention to Help Bipolar Parents to Improve Perceived Parenting Skills and Child Outcomes
}

\author{
Steven Jones \\ Lancaster University, $U K$ \\ Rachel Calam \\ University of Manchester, $U K$ \\ Matthew Sanders \\ University of Queensland, Australia
}

Peter J. Diggle

Lancaster University, $U K$

Robert Dempsey and Vaneeta Sadhnani

University of Manchester, $U K$

\begin{abstract}
Background: Children of bipolar parents are at elevated risk for psychiatric disorders including bipolar disorder. Helping bipolar parents to optimize parenting skills may improve their children's mental health outcomes. Clear evidence exists for benefits of behavioural parenting programmes, including those for depressed mothers. However, no studies have explored web-based self-directed parenting interventions for bipolar parents. Aims: The aim of this research was to conduct a pilot study of a web-based parenting intervention based on the Triple P-Positive Parenting Programme. Method: Thirty-nine self-diagnosed bipolar parents were randomly allocated to the web-based intervention or a waiting list control condition. Parents reported on their index child (entry criterion age 4-10 years old). Perceived parenting behaviour and child behaviour problems (internalizing and externalizing)
\end{abstract}

Requests for reprints to Steven Jones, Spectrum Centre for Mental Health Research, School of Health and Medicine, Lancaster University, Lancaster LA1 4YT, UK. E-mail: s.jones7@lancaster.ac.uk 
were assessed at inception and 10 weeks later (at course completion). Fifteen participants (4 control group and 11 intervention group) did not provide follow-up data. Results: Levels of child behaviour problems (parent rated; Strengths and Difficulties Questionnaire) were above clinical thresholds at baseline, and problematic perceived parenting (self-rated; Parenting Scale) was at similar levels to those in previous studies of children with clinically significant emotional and behavioural problems. Parents in the intervention group reported improvements in child behaviour problems and problematic perceived parenting compared to controls. Conclusions: A web-based positive parenting intervention may have benefits for bipolar parents and their children. Initial results support improvement in child behaviour and perceived parenting. A more definitive study addressing the limitations of the current work is now called for.

Keywords: Bipolar disorder, web intervention, parenting intervention.

\section{Introduction}

Bipolar disorder (BD) is a common long term mental health problem characterized by instability in a range of important areas including mood, sleep and behaviour that can impact on functional domains such as work and family/social relationships (Bentall and Jones, 2006; Goodwin and Jamison, 2007; Vance, Jones, Espie, Bentall and Tai, 2007). As patterns of communication, impulse control and motivation are all affected by $\mathrm{BD}$, parenting is made more difficult for those individuals (Phelan, Lee, Howe and Walter, 2006; Vance et al., 2007). Furthermore, research with children of bipolar parents (CBP) indicates that offspring experience significantly elevated risk for a wide range of psychiatric conditions, including attention deficit hyperactivity disorder, anxiety, depression, substance use, and sleep disorders in addition to rates of bipolar disorder higher than those seen in the general population (Duffy, Alda, Crawford, Milin and Grof, 2007; Jones and Bentall, 2008). Left untreated, behavioural and emotional problems in children of parents with BD can increase their risk of future mental health problems (Alloy et al., 2004; Inoff-Germain, Nottelmann and Radke-Yarrow, 1992; Vance et al., 2007). Thus in a previous study (Jones, Tai, Evershed, Knowles and Bentall, 2006) we found that although $56 \%$ of an adolescent CBP sample had current or lifetime mood symptoms on structured clinical interview, none were in receipt of psychological or psychiatric input for these difficulties. Although there is a high demand for community based parenting support, there are few evidence-based parenting interventions (Calam, Sanders, Miller, Sadhnani and Carmont, 2008; Sanders, Calam, Durand, Liversidge and Carmont, 2008) and many parents with bipolar disorder do not currently have access to these. Although it might be assumed that the difficulties observed in CBP are determined by genetic factors, psychological research indicates both that family and parental communication problems are elevated in CBP and that such problems may be related to transition to bipolar disorder (Alloy et al., 2004; Inoff-Germain et al., 1992; Vance et al., 2007). Additionally, in adolescents and adults with established bipolar disorder higher levels of expressed emotion (defined by higher levels of criticism and/or over-involvement from parents or carers) are associated with worse clinical outcomes (Butzlaff and Hooley, 1998; Miklowitz et al., 2007, 2008).

These findings suggest that interventions that improve parenting behaviour and address emerging problems in preadolescent children might in due course have the potential to prevent the development of significant difficulties in later life. Additionally, as stressful events are a well established predictor of relapse in adults with bipolar disorder, reducing the stress of 
parenting for parents with bipolar disorder may, by reducing parental exposure to stressful events, have beneficial outcomes for their own clinical course. Recently conducted quantitative and qualitative work has found significant support amongst parents with BD for self-management interventions (Backer, 2011; Murphy, 2011). These studies also found that parents with BD had a strong desire to parent well but due to their awareness of the impact of their illness on their parenting they experienced guilt and worry, and reported that they wanted parenting support. Such interventions are therefore likely to be especially beneficial if they can be delivered to large numbers of parents in self-help format focused on building on current skills and normalizing the experience of parenting challenges, irrespective of whether parents experience mental health issues. Sanders and colleagues, who developed the Triple P-Positive Parenting Programme, have successfully delivered it as a self-help intervention to parents without bipolar disorder, reporting significant gains in child and parenting outcomes across self-directed and more intensive clinician-led intervention formats (Calam et al., 2008; Sanders, Bor and Morawska, 2007; Sanders et al., 2008). Interventions of this type are delivered in formats designed to normalize the problems parents experience and to provide support around enhancing competencies rather than highlighting parental or child deficits. This approach has proved successful in engaging a wide range of families and seeks to avoid stigmatizing participants, an important consideration in the provision of preventative approaches (Sanders, 2008). The present paper describes the pilot evaluation of a web-based self-help parenting intervention based on Triple $P$ principles adapted for bipolar parents. This was based on material developed for the Triple P Parenting Media Project described in Metzler, Sanders, Rusby and Crowley (2012), with the addition of a tip sheet for parenting on detecting and coping with mood swings. This self-management approach is consistent with UK Government recommendations and priorities for public and mental health (Darzi, 2008; Department of Health, 2009, 2011) to improve health, be responsive and accessible, allow choice and control, and be empowering, as it can be used autonomously. Due to limited resources in mental health, many people with BD do not have ready access to evidence-based interventions of any type, still less specific help with parenting. Web-based self-management interventions such as the one reported here do not require formal training and can reach large numbers of people at less cost than traditional therapies and may therefore in the future have potential to address inequalities in access to care (Kazdin and Blase, 2011). A primary aim of this study is to determine whether there is any demand for an intervention of this type to this patient group. Additionally, we wish to determine effect sizes for perceived parenting and child behaviour outcomes to inform a future definitive trial. Specifically, it was hypothesized that web-based enhanced positive parenting training would, compared with a waiting list control group: i) Reduce parent ratings of child problems; and ii) Improve self-reported parenting skills.

\section{Method}

Ethical approval for the study was granted by the Senate Ethics Committee of the University of Manchester and all procedures are in accordance with the Helsinki Declaration of 1975.

\section{Participants}

Thirty-nine parents with children in the age range 4-10 years responded to advertisements for the study and completed questionnaires online. The characteristics of the parents and children 
Table 1. Parent, child and family demographic characteristics at baseline by group and completer status

\begin{tabular}{|c|c|c|c|c|}
\hline \multirow[b]{2}{*}{ Variable } & \multicolumn{2}{|c|}{ Completers } & \multicolumn{2}{|c|}{ Non-completers } \\
\hline & $\begin{array}{l}\text { Control } \\
(n=16) \\
M(S D)\end{array}$ & $\begin{array}{l}\text { Treatment } \\
(n=8) \\
M(S D)\end{array}$ & $\begin{array}{l}\text { Control } \\
(n=4) \\
M(S D)\end{array}$ & $\begin{array}{l}\text { Treatment } \\
(n=11) \\
M(S D)\end{array}$ \\
\hline \multicolumn{5}{|l|}{ Age (years): } \\
\hline Parent & $40.25(6.67)$ & $37.80(7.23)$ & $37.00(3.00)$ & $33.63(12.10)$ \\
\hline Child & $6.67(2.02)$ & $6.13(1.81)$ & $7.00(1.41)$ & $8.00(1.48)$ \\
\hline \multicolumn{5}{|l|}{ Gender: } \\
\hline Parent & $\begin{array}{l}15 \text { female; } \\
1 \text { male }\end{array}$ & 8 female; 0 male & 4 female; 0 male & $\begin{array}{l}11 \text { female; } \\
0 \text { male }\end{array}$ \\
\hline Child & $\begin{array}{c}5 \text { female; } \\
11 \text { male }\end{array}$ & $\begin{array}{l}3 \text { female; } \\
4 \text { male; } 1 \text { not } \\
\text { specified }\end{array}$ & $\begin{array}{l}0 \text { female; } \\
4 \text { male }\end{array}$ & $\begin{array}{l}5 \text { female; } \\
6 \text { male }\end{array}$ \\
\hline \multicolumn{5}{|c|}{ Parent's employment and benefit status: } \\
\hline Currently employed & 5 & 3 & 1 & 5 \\
\hline Unemployed & 11 & 5 & 3 & 6 \\
\hline Receiving benefits & 12 & 5 & 4 & 8 \\
\hline Struggling financially & 9 & 2 & 3 & 5 \\
\hline Managing financially & 7 & 6 & 1 & 6 \\
\hline \multicolumn{5}{|c|}{ Parent's highest education level: } \\
\hline No qualifications & 0 & 0 & 0 & 2 \\
\hline GCSEs/O Levels & 4 & 1 & 2 & 2 \\
\hline A Levels/BTEC & 1 & 1 & 0 & 2 \\
\hline Trade/Apprenticeship & 0 & 2 & 0 & 0 \\
\hline University degree & 10 & 4 & 2 & 5 \\
\hline Postgraduate & 1 & 0 & 0 & 0 \\
\hline \multicolumn{5}{|c|}{ Parental contact with health professionals in past 6 months: } \\
\hline Psychologist & 6 & 4 & 0 & 3 \\
\hline Psychiatrist & 12 & 7 & 4 & 10 \\
\hline Counsellor & 3 & 2 & 3 & 6 \\
\hline Social worker & 3 & 1 & 1 & 5 \\
\hline Other & 9 & 2 & 3 & 6 \\
\hline \multicolumn{5}{|c|}{ Regular contact with health professionals for child emotional or behavioural problems: } \\
\hline Yes & 4 & 0 & 1 & 3 \\
\hline No & 12 & 8 & 3 & 8 \\
\hline
\end{tabular}

at baseline are shown in Table 1 . There were 15 boys and 5 girls (follow-up data obtained from 11 boys and 5 girls) in the control condition and 10 boys and 8 girls (follow-up data obtained from 4 boys and 4 girls) in the treatment group (there was 1 child for whom parents did not record gender information). Neither age nor gender distributions differed between the control and intervention conditions. Inclusion criteria were: i) parent self-reported diagnosis of bipolar disorder and score on the Mood Disorders Questionnaire of > 9; ii) age of child (4-10 years old). 


\section{Measures}

Demographic data were collected using the Family Background Questionnaire (FBQ) adapted for UK samples as used in previous online parenting research (Calam et al., 2008).

\section{Parental diagnostic and symptom measures}

Mood Disorder Questionnaire (MDQ; Hirschfeld et al., 2000). The MDQ was developed to aid diagnosis of bipolar disorders. In the original version it covers symptom endorsement of 13 manic/hypomanic symptoms (Section 1), symptom clustering (Section 2) and severity of problem caused (Section 3). However, recent research has supported the use of Section 1 alone to avoid incorrect screening out of individuals experiencing bipolar II symptoms (Twiss, Jones and Anderson, 2008). This research indicated that the optimal cut-off score was a score of 9 or more endorsed symptoms without applying the supplementary questions (sensitivity of 0.90 and 0.88 for bipolar I and bipolar II groups respectively with a specificity of 0.90).

The Center for Epidemiological Studies Depression Scale (CES-D; Radloff, 1991). CES-D is a 20-item self-report depression scale that detects current depressive symptoms. A score above 16 indicates possible depression (Radloff, 1991). Cronbach's alpha for CES-D in the current sample was 0.95 .

Internal States Scale (ISS; Bauer et al., 1991). This is a self-report questionnaire assessing manic and depressive symptoms. Its 15 items contribute to four subscales: Activation (ISSA), Well-Being (ISS-WB), Perceived Conflict (ISS-PC), and Depression (ISS-D). Each item relates to the preceding 24 hours. Ratings are made on a $100 \mathrm{~mm}$ visual analogue scale with anchor descriptions of "Not at all/Rarely" at one extreme and "Very much so/Much of the time" at the other. This measure is widely used and has good internal reliability and validity. ISS-A score above 200 indicates possible mania; ISS-WB below 125 is indicative of possible depression (Bauer et al., 1991). Cronbach's alphas for ISS-A and ISS-WB, the two subscales focused on for this study, were 0.87 and 0.83 respectively.

\section{Child behaviour and perceived parenting measures}

Strengths and Difficulties Questionnaire (SDQ; Goodman, 2001). This is a widely used 25-item questionnaire with good psychometric properties generating dimensional scores for total difficulties [clinical cut-off 14 (borderline)/17 (abnormal)]; emotional symptoms [clinical cut-off 4 (borderline)/5(abnormal)]; conduct problems [clinical cutoff 3(borderline)/4 (abnormal)]; hyperactivity [clinical cut-off 6 (borderline)/7 (abnormal)]; peer problems [clinical cut-off 3 (borderline)/4 (abnormal)], and prosocial behaviour [clinical cut off 5 (borderline)/4 (abnormal)]. Note that the total difficulties score for SDQ does not include scores from the prosocial behaviour subscale. The measure has proved capable of identifying children with depressive, conduct and hyperactive disorders. It has shown a specificity of $94.6 \%$ (95\% CI 94.1-95.1\%) and sensitivity of $63.3 \%$ (59.7$66.9 \%$ ) in identifying children with a psychiatric diagnosis (Goodman, Ford, Simmons, Gatward and Meltzer, 2000). Cronbach's alpha for SDQ total score for this sample was 0.72 . 
The Parenting Scale (PS; Arnold, O’Leary, Wolff and Acker, 1993). This 30-item questionnaire measures perceived dysfunctional discipline styles in parents. Test-retest reliabilities for the three subscales are .83 (Laxness), .82 (Overreactivity) and .79 (Verbosity). It reliably discriminates parents of clinical and non-clinical children (Arnold, et al., 1993). Cronbach's alpha for PS total score in the current sample was 0.84 .

\section{Procedure}

Parents with a self-reported clinical diagnosis of bipolar disorder with 4- to 10-year-old children were invited to participate in the study. Recruitment concentrated on Bipolar UK (previously the Manic Depression Fellowship), the national charity dedicated to the support of people with bipolar disorder and their families. Information on the study was provided via publicity in newsletters, e-mail circulars, and at local meetings of the MDF: The Bipolar Organization (a UK self-help organization for people with bipolar disorder) and through the MDF national magazine (Pendulum). A web link for the study was included in all advertising. All questionnaires were completed on line. Parents were randomized either to an intervention condition that received a web-based Triple $\mathrm{P}$ intervention or to a waiting list control. Randomization to group was done on the basis of a predetermined random sequence in blocks of six held in a sealed envelope within the website. Each participant was automatically allocated to the next available number (1 for control, 2 for treatment) upon registration with the site. In the latter condition participants were provided with access to intervention materials after their follow-up assessment but no data were collected on their use due to limited resources. All measures were completed online. A CONSORT diagram is provided in Figure 1, illustrating recruitment and retention figures for both arms of the trial. The study originally recruited 54 participants, but of these 15 had index children too young to complete the available version of SDQ and were therefore not included in this report.

\section{Web-based parenting intervention}

Participants in the intervention group were provided with a 10-week course on managing child behaviour. This consisted of written material in the form of a book that was posted to them at the beginning of the intervention (Markie-Dadds, Sanders and Turner, 1999) as well as web-based information (released weekly to coincide with the 10 weekly chapters of the book) in written video and audio format that provided additional support for parents as they worked through the self-help workbook. The web material was taken from the Triple P Parenting Media Series that was developed for the Triple P Parenting Media Project described in Metzler et al. (2012). Both the workbook and web resources covered a number of key areas including:

- Encouraging desirable behaviour (through reinforcement, modelling and consistency);

- Coping with difficult behaviour (through clear ground rules and proportionate logical consequences including, where appropriate, planned ignoring and time out);

- Managing sleep routines (through a clear regular bedtime routine, consistently reinforcing pro-sleep behaviours and ignoring/extinguishing non-sleep behaviours); 


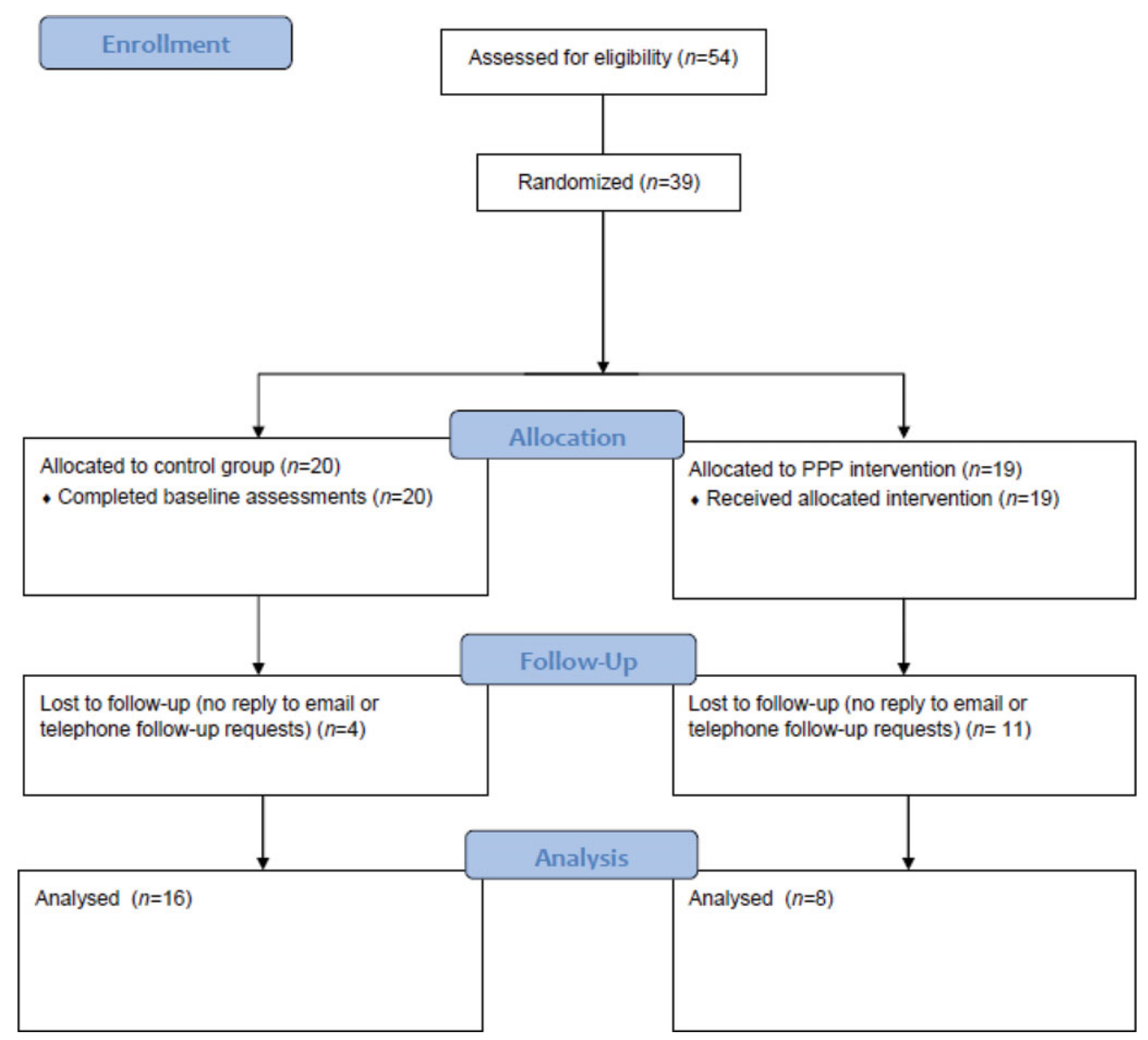

Figure 1. (Colour online) CONSORT diagram showing participant flow through the study

- Coping with stress in the family (through identifying parental stress and addressing it with relaxation and thought challenge approaches so that the parent can apply the previous principles of positive parenting consistently).

Material in each of these areas was based on behavioural parenting principles evaluated in a wide range of Triple P studies (Calam et al., 2008; Sanders et al., 2007, 2008). The only amendment to the materials described above for the current study was to provide an additional tip sheet, developed for this study, specifically dealing with how parents might detect and cope with ups and downs of their own mood.

\section{Analysis plan}

Demographic and symptom information was compared using $t$-tests, ANOVA and KruskalWallis tests as appropriate for continuous/ranked data and $\chi^{2}$ for categorical data. End of 
therapy data on the two primary outcomes, perceived parenting behaviour (measured by PS) and child behaviour problems (measured by SDQ), were obtained on only 24 out of 39 eligible participants. Crude dropout rates were 4 out of 20 and 11 out of 19 in the control and treatment groups respectively, a significant difference $\left(X^{2}=5.39\right.$ on $\left.1 d f, \mathrm{p}=0.01\right)$.

A random effects model with random intercept was used to evaluate the effect of the treatment on PS and on SDQ. In both cases, the model was fitted by maximum likelihood, adjusting for the possible effects of parental depression (CESD, ISS-WB), child age, mania symptoms (ISS-A) and whether the child was in contact with professional care services (from FBQ) in the analysis. This made the analysis somewhat robust to dropouts, in the sense that it adjusted automatically for any dependence between the baseline score and the probability of dropout.

\section{Results}

\section{Demographic information}

Forty-one percent $(n=16)$ of children were living with both their biological parents, whilst $36 \%$ ( $n=14)$ were being raised by a single parent at the time of assessment. Detailed demographic information is presented in Table 1 for treatment and control groups with respect to completer status. Statistical testing indicated no significant differences between groups for parental or child age or gender. In the completer groups the ratio of boys to girls was higher for controls than those receiving treatment but again this difference was not statistically significant. Groups also did not differ with respect to parental employment or financial status, education level or parental or child contact with a health professional. The majority of parents assessed were unemployed ( $n=25$ overall; $n=16$ completers) and on benefits $(n=29$ overall; $n=17$ completers) with almost half of the total sample and over half of completers struggling financially ( $n=19$ overall; $n=11$ completers). The majority of parents were educated to degree level or above ( $n=22$ overall; $n=15$ completers) and were receiving care from at least one mental health professional (overall $n=34$; completers $n=20$ ), with most of these contacts including a psychiatrist (overall $n=33$; completers $n=19$ ). In contrast, very few children were receiving professional help from paediatric, psychological or specialist school services (overall $n=8$ : completers $n=4$ ). Self-report data for parents and children are presented in Table 2. Parental self-reported diagnosis of bipolar disorder (100\%) was consistent with MDQ scores substantially above clinical cut-off in all cases. Parents also reported experiencing significant depressive symptoms as assessed by both the CES-D and the ISS-W. Groups did not differ significantly on mood scores.

\section{Parent assessment of child behaviour and perceived parenting}

At inception, children were rated as having internalizing and externalizing problems at clinically significant levels on the SDQ. Mean SDQ total score was above the clinical threshold as was the conduct problems subscale; mean emotional symptoms, hyperactivity and peer problems were all at the borderline threshold (Goodman, 2001). Of the participants for whom pre- and post-data were available 11/16 controls and 8/8 treatment participants had scores at or above the borderline threshold at inception: at follow-up 8/11 controls remained at this level compared with $3 / 8$ treatment group participants. 
Table 2. Average ratings for parental mood and parenting behaviour and child behaviour problems at baseline by condition and completion of follow-up assessment

\begin{tabular}{lcclcc}
\hline & Completers & & & \multicolumn{2}{l}{ Non-completers } \\
\cline { 2 - 3 } \cline { 5 - 6 } & Control $(n=16)$ & Treatment $(n=8)$ & & Control $(n=4)$ & Treatment $(n=11)$ \\
Variable & $M(S D)$ & $M(S D)$ & & $M(S D)$ & $M(S D)$ \\
\hline CES-D & $40.38(14.23)$ & $36.75(12.40)$ & & $44.00(12.83)$ & $35.55(18.37)$ \\
ISS activation & $155.00(112.92)$ & $186.25(144.63)$ & & $240.50(155.86)$ & $245.64(162.15)$ \\
ISS well-being & $88.38(60.99)$ & $114.00(98.27)$ & & $111.00(75.62)$ & $144.45(83.95)$ \\
MDQ & $12.44(1.15)$ & $11.50(1.44)$ & & $13.00(.00)$ & $12.64(0.67)$ \\
Child age & $6.63(1.96)$ & $6.13(1.81)$ & & $7.00(1.41)$ & $8.00(1.48)$ \\
SDQ (Time 1) & $16.88(6.83)$ & $20.25(3.54)$ & & $15.00(4.24)$ & $20.00(2.79)$ \\
PS (Time 1) & $3.82(0.57)$ & $3.37(0.75)$ & & $3.15(0.60)$ & $3.37(0.75)$ \\
\hline
\end{tabular}

Notes: CES-D (Center for Epidemiological Studies Depression Scale); ISS (Internal States Scale); MDQ (Mood Disorder Questionnaire); SDQ (Strengths and Difficulties Questionnaire); PS (Parenting Scale)

Parents' PS ratings indicated problematic parenting behaviour within the clinical range, as the mean PS score was above that for the clinical sample in the original development study for the measure and for a more recent study in which the children recruited all scored above clinical thresholds for the Eyberg Child Behaviour Inventory (Arnold et al., 1993; Calam et al., 2008).

\section{Outcomes for web-based parenting self-help intervention}

Figures 2 and 3 show scores (+/- two pointwise standard errors) at baseline and end of treatment (10 weeks post baseline) for SDQ and PS respectively. The comparison of the treatment and control groups with respect to SDQ score indicated non-significant differences between groups at baseline (mean difference $=3.31, S E=3.81, p<.09$ ). There was a significant change in SDQ score for treatment group (slope $=-9.18, S E=2.33, p<.001$ ) but not for control group (slope $=-0.74, S E=3.47, p<.68$ ). Slope in treatment group was significantly more negative than in control group, with a large effect size (difference in slope $=8.44, S E=5.72, p<.004 ; d=1.00)$.

The same comparisons with respect to PS score again showed a non-significant baseline difference between groups (mean difference $=-0.21, S E=0.24, p=.39$ ). There was a significant change in PS score for treatment group (slope $=-0.91, S E=0.45, p<.001$ ) but not for control group (slope $=0.03, S E=0.33, p=.85$ ). Slope in treatment group was significantly more negative than in control group, with a moderate effect size (difference in slope $=0.94, S E=0.56, p<.001 ; d=0.73$ ).

\section{Discussion}

A primary aim of the current study was to indicate whether there was potential demand for a parenting intervention amongst parents with bipolar disorder. We were able to recruit 54 participants for this trial from a limited recruitment strategy focusing on members of 


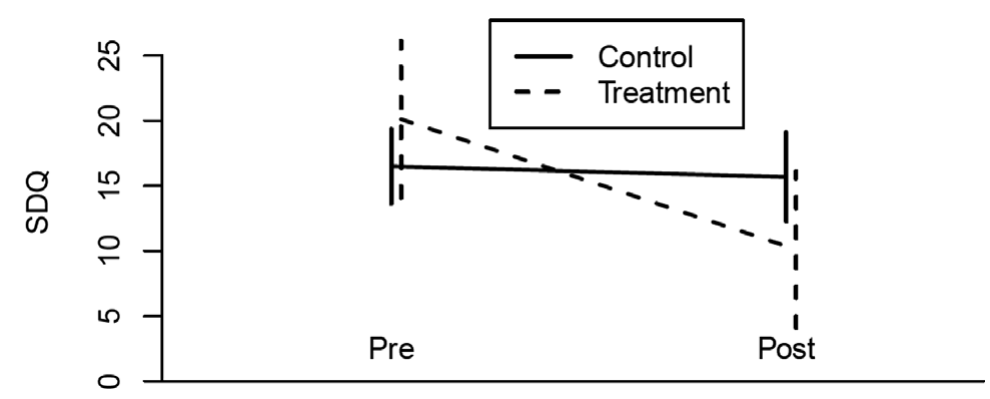

Figure 2. Total Strengths and Difficulties Questionnaire scores comparing treatment and control group pre- and post-intervention

Note: $\mathrm{SDQ}=$ Total Strengths and Difficulties Questionnaire Score

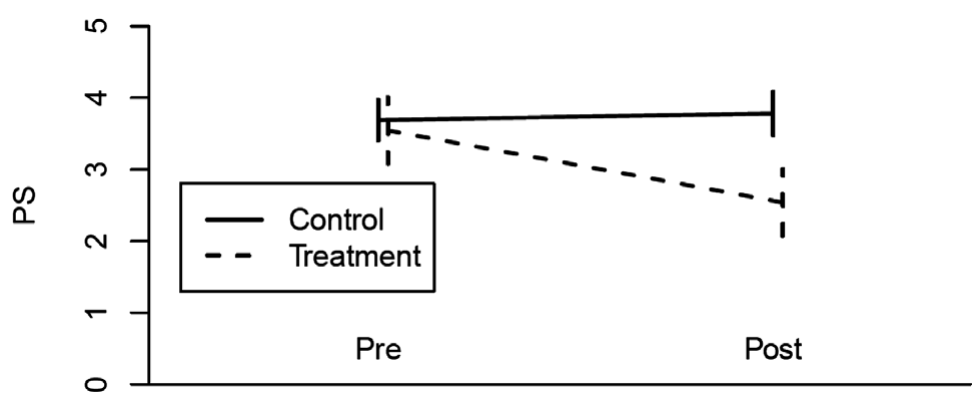

Figure 3. Total Parenting Scale scores comparing treatment and control group pre- and post-intervention

Note: PS $=$ Total Parenting Scale Score

Bipolar UK, although only 39 had children within the target age range. This suggests that there is at least some interest in parenting-support amongst bipolar parents, although large scale research in the future will evaluate this more formally. The present study suggests that it is possible to deliver a web-based parenting approach to bipolar parents and also that this approach impacts on both child behaviour and perceived parenting practices. However, consistent with this being a pilot study there are issues that need to be considered in interpreting the findings. The parents participating in this study were a self-selecting group and as self-help group members they might be unrepresentative in their levels of motivation and readiness to change. However, although most were in a stable family setting, most were not employed and almost half were struggling financially, suggesting that at least a proportion of the participants were experiencing some of the severe social and functional difficulties that some people with bipolar disorder experience. Additionally, this group of parents reported significant current depressive symptoms on both self-report measures used in this study, significant difficulties in perceived parenting and high levels of problematic behaviour in their children. For comparison, a study of 51 referrals to three English Family Support and Child and Adolescent Mental Health Services reported mean Total SDQ scores of 21 or 22 (Vostanis, Anderson and Window, 2006). A pre-intervention mean Total SDQ score of 12 was reported for children in families taking part in a randomized controlled trial 
of a parenting programme with recruitment through general practices and pre-screening for behaviour problems prior to entry (Stewart-Brown et al., 2004). The relatively high SDQ scores in the current study are particularly striking as the sample was not selected on the basis of child emotional and behavioural problems and underscores the need for an intervention that enhances child behavioural and emotional well-being for this group of children (especially as in the current sample only $20 \%$ of parents reported accessing care for their parenting issues or their children's behaviour problems). As noted in the Procedure section we originally recruited a sample including children under 4 years old. As these children are too young to be appropriately rated on the SDQ we excluded these from the report.

With relatively brief and limited publicity this study successfully recruited 39 participants within the target age range, which suggests interest in this approach from bipolar parents. The study was less successful with respect to retention; $38 \%$ of the sample were lost to follow-up, with more lost from the intervention compared to the control group (57\% vs. $20 \%$ ). Statistical comparisons indicated no significant demographic differences for parents or children with respect to group or completer status; however it is worth noting that the small sample sizes reduce power to detect differences and that completer controls had a higher ratio of boys to girls and a higher rate of contact with professional carers for child problems than completers in the treatment arm. In retrospect, we believe that a significant contributing factor to the loss of follow-up was providing individuals in the therapy arm with all the written therapy materials at the beginning of the intervention, thus reducing their incentive to remain in the study assessments to completion. Evidence from the self-management literature generally suggests that retention is better in supported approaches whether or not these are face to face and irrespective of the level of training of the individual providing the support (Gellatly et al., 2007). Additional elements likely to have improved retention in this study might have been delivery of written materials in a staged fashion to match web access procedure and providing participants with financial compensation for their participation in assessments. We were not able to ask participants who dropped out for their reasons directly as those who dropped out stopped responding to communication from the trial team. This means that we are not able to rule out the possibility that some participants in the treatment arm dropped out because they found aspects of the intervention unhelpful or aversive. All of these are elements that we intend to address in future research. Significant attrition (around $60 \%$ to 6-month follow-up) has also been observed in a previous study of self-management support for parenting offered to a general population sample (Calam et al., 2008) which offered more support and was publicized via a national prime time TV series. Such attrition issues are normally considered against the potential such interventions have to offer access to care for people who are typically not receiving this through more established channels.

Although Triple $\mathrm{P}$ is a widely used intervention to prevent conduct disorder in children, this is the first report applying any version of Triple $\mathrm{P}$ in a group of bipolar parents. In the present study web-based self-directed Triple $\mathrm{P}$ was offered to parents, providing them with structured guidance on effective approaches to enhance their perceived parenting and successfully address their child's behaviour problems. The current results suggest that both perceived parenting and child behaviour can feasibly be improved by offering parents with bipolar disorder a self-help web-based intervention of this type. An advantage of this form of self-help is the flexibility it offers to deliver information through a range of modalities - in the present study through text, video and audio files. It is also consistent with previous research in which parents with bipolar disorder have expressed interest in receiving self-management 
support for parenting issues (Backer, 2011; Murphy, 2011) and with wider national policy on increasing access and choice in care for people with long term health problems (Darzi, 2008; Department of Health, 2009, 2011).

Although improvements with moderate to large effect sizes were obtained in both perceived parenting behaviour and child behaviour problems, it is not clear how long the benefits of the intervention persist and how replicable these effects are in a larger sample with balanced retention across treatment and control arms. Future research should therefore evaluate the intervention over longer follow-up periods in a larger scale study that addresses the issue of differential drop-out identified in the current study. Additionally, parental experience of bipolar was based on self-report of a clinical diagnosis of bipolar disorder, membership of a national self-help organization for people with bipolar disorder, and MDQ clinical threshold scores. MDQ has been used successfully in community and psychiatric samples in previous studies (Hirschfeld et al., 2000, 2003; Twiss et al., 2008) although recent research reports that in a large mixed psychiatric sample a positive MDQ screen was associated with both bipolar disorder and borderline personality disorder (Zimmerman et al., 2010). Our own research, albeit with a small qualitative sample, indicates that when participants selfreport a clinical diagnosis of bipolar disorder and have a positive MDQ screen they do then meet DSM-IV criteria for bipolar disorder (Lobban, Taylor, Murray and Jones, 2012). It would therefore be helpful for future evaluations of this intervention to employ formal diagnostic interview assessments of parents, both to clarify primary diagnosis and current mood state and to provide more information on possible comorbid conditions. It might be expected that improvement in child behaviour would also be associated with improvements in parental outcomes as the general family environment improves. Previously it has been shown that Triple $\mathrm{P}$ clinician-led behavioural family interventions can reduce parental depression and improve child behaviour with gains sustained over a 6-month period (Sanders and McFarland, 2000). It would therefore be important in future research with this web-based self-management approach to test whether the intervention had enhanced important clinical outcomes for the parents themselves.

If future research confirms the current promising improvements in child and perceived parenting behaviour it would also be of interest to explore their longer term impact on the increased risk of transition to bipolar disorder. Interventions of this type have the potential to be delivered to large numbers of individuals at low cost per person. This is essential as it may be necessary to deliver preventative interventions to large numbers of children of bipolar parents to significantly impact on transition rates, as recent studies differ on transition rates to diagnosable bipolar disorder by early adulthood in CBP; for example, Hillegers et al. (2005) reported $10 \%$ transition whilst Birmaher et al. (2009) reported an $18 \%$ transition rate.

\section{Acknowledgements}

The authors wish to thank Austin Lockwood for his work in setting up the website used in this paper.

\section{References}

Alloy, L. B., Abramson, L. Y., Gibb, B. E., Crossfield, A. G., Pieracci, A. M., Spasojevic, J., et al. (2004). Developmental antecedents of cognitive vulnerability to depression: review of findings 
from the cognitive vulnerability to depression project. Journal of Cognitive Psychotherapy, 18, 115133.

Arnold, D. S., O'Leary, S. G., Wolff, L. S. and Acker, M. M. (1993). The Parenting Scale: a measure of dysfunctional parenting in discipline situations. Psychological Assessment, 5, 137144.

Backer, C. (2011). "It's Like Being on the Other Side of the World with Mummy": a qualitative study exploring children's experiences of living with a parent with Bipolar Disorder. Unpublished Clinical Psychology Thesis, The University of Manchester.

Bauer, M. S., Crits-Christoph, P., Ball, W. A., Dewees, E., McAllister, T., Alahi, P., et al. (1991). Independent assessment of manic and depressive symptoms by self rating. Archives of General Psychiatry, 48, 807-812.

Bentall, R. and Jones, S. H. (2006). The Psychology of Bipolar Disorder: new developments and research strategies. New York: Oxford University Press.

Birmaher, B., Axelson, D., Monk, K., Kalas, C., Goldstein, B., Hickey, M. B., et al. (2009). Lifetime psychiatric disorders in school-aged offspring of parents with bipolar disorder: the Pittsburgh bipolar offspring study. Archives of General Psychiatry, 66, 287-296.

Butzlaff, R. L. and Hooley, J. M. (1998). Expressed emotion and psychiatric relapse: a meta-analysis. Archives of General Psychiatry, 55, 547-552.

Calam, R., Sanders, M. R., Miller, C., Sadhnani, V. and Carmont, S. A. (2008). Can technology and the media help reduce dysfunctional parenting and increase engagement with preventative parenting interventions? Child Maltreatment, 13, 347-361.

Darzi, A. (2008). High Quality Care For All: next stage review final report. London: DoH.

Department of Health (2009). New Horizons: a shared vision for mental health. London: DoH.

Department of Health (2011). No Health Without Mental Health: a cross-government mental health outcomes strategy. London: DoH.

Duffy, A., Alda, M., Crawford, L., Milin, R. and Grof, P. (2007). The early manifestations of bipolar disorder: a longitudinal prospective study of the offspring of bipolar parents. Bipolar Disorders, 9, 828-838.

Gellatly, G., Bower, P., Hennessey, S., Richards, D., Gilbody, S. and Lovell, K. (2007). What makes self-help interventions effective in the management of depressive symptoms? Meta-analysis and meta-regression. Psychological Medicine, 37, 1217-1228.

Goodman, R. (2001). Psychometric properties of the Strengths and Difficulties Questionnaire. Journal of the American Academy of Child and Adolescent Psychiatry, 40, 1337-1345.

Goodman, R., Ford, T., Simmons, H., Gatward, R. and Meltzer, H. (2000). Using the Strengths and Difficulties Questionnaire (SDQ) to screen for child psychiatric disorders in a community sample. British Journal of Psychiatry, 177, 534-539.

Goodwin, F. K. and Jamison, K. R. (2007). Manic-Depressive Illness. New York: Oxford University Press.

Hillegers, M. H., Reichart, C. G., Wals, M., Verhulst, F. C., Ormel, J. and Nolen, W. A. (2005). Five-year prospective outcome of psychopathology in the adolescent offspring of bipolar parents. Bipolar Disorders, 7, 344-350.

Hirschfeld, R. M., Calabrese, J. R., Weissman, M. M., Reed, M., Davies, M. A., Frye, M. A., et al. (2003). Screening for bipolar disorder in the community. Journal of Clinical Psychiatry, $64,53-59$.

Hirschfeld, R. M., Williams, J. B., Spitzer, R. L., Calabrese, J. R., Flynn, L., Keck, P. E. Jr., et al. (2000). Development and validation of a screening instrument for bipolar spectrum disorder: the Mood Disorder Questionnaire. American Journal of Psychiatry, 157, 1873-1875.

Inoff-Germain, G., Nottelmann, E. D. and Radke-Yarrow, M. (1992). Evaluative communications between affectively ill and well mothers and their children. Journal of Abnormal Child Psychology, $20,189-212$. 
Jones, S. and Bentall, R. P. (2008). A review of potential cognitive and environmental risk markers in children of bipolar parents. Clinical Psychology Review, 28, 1083-1095.

Jones, S., Tai, S., Evershed, K., Knowles, R. and Bentall, R. (2006). Early detection of bipolar disorder: a pilot familial high-risk study of parents with bipolar disorder and their adolescent children. Bipolar Disorders, 8, 362-372.

Kazdin, A. E. and Blase, S. L. (2011). Rebooting psychotherapy research and practice to reduce the burden of mental illness. Perspectives on Psychological Science, 6, 21-37.

Lobban, F., Taylor, K., Murray, C. and Jones, S. (2012). Bipolar disorder is a two-edged sword: a qualitative study to understand the positive edge. Journal of Affective Disorders, 141, 204-212.

Markie-Dadds, C., Sanders, M. and Turner, K. M. T. (1999). Every Parent's Self Help Workbook. Brisbane, Australia: Families International Publishing.

Metzler, C. W., Sanders, M. R., Rusby, J. C. and Crowley, R. N. (2012). Using consumer preference information to increase the reach and impact of media-based parenting interventions in a public health approach to parenting support. Behavior Therapy, 43, 257-270.

Miklowitz, D. J., Axelson, D. A., Birmaher, B., George, E. L., Taylor, D. O., Schneck, C. D., et al. (2008). Family-focused treatment for adolescents with bipolar disorder: results of a 2-year randomized trial. Archives of General Psychiatry, 65, 1053-1061.

Miklowitz, D. J., Otto, M., Frank, E., Reilly-Harrington, N., Wisniewski, S., Kogan, J., et al. (2007). Psychosocial treatments for bipolar depression: a 1-year randomized trial from the Systematic Treatment Enhancement programme. Archives of General Psychiatry, 64, 419-427.

Murphy, R. (2011). A Qualitative Investigation of the Experience of Parenting with Bipolar Disorder. Unpublished Clinical Psychology Degree Thesis, University of Manchester.

Phelan, R., Lee, L., Howe, D. and Walter, G. (2006). Parenting and mental illness: a pilot group programme for parents. Australasian Psychiatry, 14, 399-402.

Radloff, L. S. (1991). The use of the Centre for Epidemiologic Studies Depression Scale in adolescents and young adults. Journal of Youth and Adolescence, 20, 149-166.

Sanders, M. (2008). Triple P-Positive Parenting Program as a public health approach to strengthening parenting. Journal of Family Psychology, 22, 506-517.

Sanders, M., Bor, W. and Morawska, A. (2007). Maintenance of treatment gains: a comparison of enhanced, standard, and self-directed Triple P-Positive Parenting Program. Journal of Abnormal Child Psychology, 35, 983-998.

Sanders, M., Calam, R., Durand, M., Liversidge, T. and Carmont, S. A. (2008). Does selfdirected and web-based support for parents enhance the effects of viewing a reality television series based on the Triple P-Positive Parenting Programme? Journal of Child Psychology and Psychiatry, 49, 924-932.

Sanders, M. and McFarland, M. (2000). Treatment of depressed mothers with disruptive children: a controlled evaluation of cognitive behavioral family intervention. Behavior Therapy, 31, 89-112.

Stewart-Brown, S., Patterson, J., Mockford, C., Barlow, J., Klimes, I. and Pyper, C. (2004). Impact of a general practice based group parenting programme: quantitative and qualitative results from a controlled trial at 12 months. Archives of Disease in Childhood, 89, 519-525.

Twiss, J., Jones, S. and Anderson, I. (2008). Validation of the Mood Disorder Questionnaire for screening for bipolar disorder in a UK sample. Journal of Affective Disorders, 110, 180-184.

Vance, Y., Jones, S., Espie, J., Bentall, R. and Tai, S. (2007). Parental communication style and family relationships in children of bipolar parents. British Journal of Clinical Psychology, 47, 355359.

Vostanis, P., Anderson, L. and Window, S. (2006). Evaluation of a family support service: short-term outcome. Clinical Child Psychology and Psychiatry, 11, 513-528.

Zimmerman, M., Galione, J. N., Ruggero, C. J., Chelminski, I., Young, D., Dalrymple, K., et al. (2010). Screening for bipolar disorder and finding borderline personality disorder. Journal of Clinical Psychiatry, 71, 1212-1217. 